\title{
Oral Health Status and Treatment Needs Of Inmates in District Jail of Jaipur City - A Cross Sectional Study.
}

\author{
Dr. Anup N. ${ }^{1}$, Dr. Gautam Biswas ${ }^{2}$, Dr. Preeti Vishnani ${ }^{3}$, Dr. Swasti Tambi ${ }^{3}$, \\ Dr. Siddharth Acharaya ${ }^{3}$, Dr. Himanshu Kumawat ${ }^{3}$. \\ Professor \& HOD, Senior Lecturer, Post-Graduate
}

\begin{abstract}
Objectives: To assess the oral health status and treatment needs of inmates of, District Jail Jaipur. Materials And Methods: A cross sectional study was carried out on the inmates $(N=870)$ in the district jail of Jaipur. Proforma related to general demographic information was filled by the examiner and the subjects were clinically examined using WHO 1997 "Oral Health Assessment form.

Results: This study revealed that $92.5 \%$ of the inmates were male. $53.8 \%$ never visited the dentist \& $87 \%$ never received any type of dental care during imprisonment. Prevalence of pro- mucosal lesion was 59.8\%. Inmates had poor periodontal conditions and 79\% inmates had dental caries with mean DMFT of 4.79. Conclusion: Periodontal disease, mucosal lesions and dental caries are major public health problem among the inmates, which require special attention and efforts from government and other organizations to meet their treatment needs.
\end{abstract}

Key words: prison inmates. Dental caries, loss of attachment, treatment need

\section{Introduction}

Health is a fundamental right of every individual and oral health is an integral part of general health. Various factors are responsible for maintenance of good oral health. Socio economic status, occupation, education are playing major role in maintenance of good oral health. Access is one of the main barriers of health care delivery system which we want to overcome by primary health care.(1)

Each population group needs different approach for health care. One of the strategies in public health is to identify unique population groups, study their health problems and explore methods for health care. Prisoners make a special group of population as they are different from other people in context of their "freedom of movement". (2) The majority of prisoners are those who come from a context already shaped by social exclusion. Among other things, they are likely to be members of an ethnic minority, have limited education and a history of instability, unemployment or underemployment, substandard diet and housing conditions and inferior medical access.(2)

The prisoners area psychologically, socially, morally and economically affected group which makes them to neglect their general as well as oral health. It is generally acknowledged from extensive research that prisoners are vulnerable to a wide range of health problems, most commonly alcohol and drug abuse, smoking, chronic diseases, mental illness, psychosocial and psychiatric problems. They are at a higher risk of violence among themselves, which results in high chronic stress levels, which may deteriorate the physical and mental health. (3) Added to this the facilities available are not up to the satisfactory level and therefore the oral health status of prisoners is affected to a marked extent.(4)

Many prisoners enter prison with poor oral health requiring emergency treatment. This may be due to limited knowledge about good oral health practices. Substance misuse contributes to high levels of tooth decay and gum disease. Excessive alcohol consumption, particularly spirits, and tobacco use increase the prevalence and severity of periodontal disease and are by far the greatest risk factors for oral cancer. (5)

The prison population is a unique and challenging one with many health problems, including poor oral health. The prisoners in jail have a different lifestyle; routine dental care and daily oral hygiene are not in their regular component of life style. Now there is a growing recognition that there is a direct link between oral health and life- style related diseases such as heart disease, arthritis etc. This lack of attention in maintaining oralhygiene is reflected in their over- all health status. An assessment of their oral health is required, as there is a need to be more attentive to oral health promotion of these prisoners as they will be re- turning to the general community. (4)

Very few studies have been conducted in India regarding oral health status of prison inmates. Also there is no information about the oral health status and treatment need of inmates of District Jail, Jaipur. Considering all these reasons this study was carried out to assess the oral health status and treatment needs of prisoners of District Jail, Jaipur. 
The present study is a cross-sectionalstudy conducted to assess the Oral Health Status and Treatment needs of Inmates of District Jail, Jaipur.

\section{Materials And Methods}

\section{Source of Data}

Data was collected through a survey which included clinical examination and a questionnaire.

\section{Study group}

Those persons, who were sentenced (inmates), were included in the study group.

Information about study group

A total of 870 convicts of the jail aged 18- 85 years were examined. Both male and female inmates were included in the study $($ Male $=805$, Female $=65)$.

\section{Inclusion criteria}

-All the inmates who were willing to give the consent were included in the study.

-Inmates who were imprisoned for more than 1 year were included.

Exclusion criteria

The subjects who did not give their con- sent for oral examination were excluded.

Sampling methodology

Purposive sampling (6) -Purposively selecting the individuals for the study. The group of individuals who were actually available for the investigations (All the inmates).

\section{Ethical Clearance}

Before starting the study, ethical clearance was obtained from the ethical committee of Jaipur Dental College, Jaipur.

Official Permission

Prior permission was taken from the Superintendent of District Jail, Jaipur, to conduct the study among all the inmates.

\section{Informed Consent}

Written consent was taken from the in- mates before their participation in the study in order to prevent any inconvenience and to obtain their cooperation.

\section{Proforma}

The data was recorded on a modified WHO 1997 proforma, which included pretested validated questions regarding Education, Occupation, Period of Imprisonment, OralHygiene Practices and Dietary Habits, Oro-Mucosal Lesions, Dental Fluorosis, Community Periodontal Status, Dental Caries and Prosthetic Status according to the criteria of modified WHO 1997 proforma. (7)

Training and Calibration of the examiner: Before the starting of the survey, the guide calibrated the investigator regarding the WHO criteria for diagnosing the oral dis- ease. The mean Kappa co-efficient values for intra-examiner reliability with respect to Kappaco-efficientofalltheindicesused in the WHO Oral Health Assessment for- mat was 0.80 .

Training of recording assistant

The examiner was assisted by a recording assistant who was trained to write codes clearly. The instructions were given to the assistant about how to record the data on the assessment form and other entries correctly.

\section{Pilot study}

Pilot study was carried before starting the mainstudytocheckfeasibilityofproforma. The data of the pilot study was not included in the main study and the necessary modifications were made in the final proforma.

\section{Details of clinical examination}

Armamentarium used included PMT sets, WHO Probe, Disposable Gloves and Mouth Masks, Concentrated Sterilizing Solution, Kidney trays, Recording forms and Pen Torch.

\section{Examination area}

The investigator himself carried out the clinical examination throughout the study. The inmates were examined in the hospital of jail. Each subject was made to sit on a chair with examiner standing behind or in front of the chair and the examination was carried out using natural light. All the data was recorded by the recording assist- ant. The recording assistant was seated in front of the examiner, so that the codes being recorded were seen by the examiner. 


\section{Clinical examination}

The clinical examination of all the subjects was done by the examiner himself and the data was recorded based on WHO standardcriteria.WHO Oral Health Assessment Form, 1997(7) was used to data from each subject. These forms have been designed to facilitate examination of all age groups for the assessment of prevalence of oraldisease and treatment needs. Standardcodes were used for all sections of the formwith each code assigned to an oral condition. The codes range from 0 to 9.

\section{Clinical assessment}

In order to ensure that all conditions weredetected and diagnosed, the clinical examinationfollowed the order of the assessmentform.

\section{Referral}

Those subjects who were suffering frompain or infection and who needed immediateattention or routine treatment werereferred to civil hospital Jaipur.

\section{Statistical Analysis}

The statistical procedure was carried out in2 steps.

- Data compilation and presentation

- $\quad$ Statistical analysis

\section{Data compilation and presentation}

The data obtained was compiled systematically,transformed from a pre-coded proformato a computer and a master tablewas prepared. The total data was distributedmeaningfully and presented as individualtables along with graphs.

\section{Statistical analysis}

Descriptive statistical analysis has been carriedout in the present study. Results oncontinuous measurements are presentedon Mean \pm SD (Min-Max) and results oncategorical measurements are presented inNumbers (\%). Significance is assessed at5\% level of significance. $(\mathrm{p}<0.05)$. Chisquare and ANOVA tests were used.

\section{Statistical Software}

The statistical software namely SPSS 19.0was used for analysis of the data andMicrosoft excel was used to generate results.

\section{Results}

A cross sectional descriptive survey was conducted to assess the oral health status and treatment needs of inmates of District Jail, Jaipur city, Rajasthan, India. A total of 870 inmates were examined. The data was collected during the month of November 2013 to January 2014.

\section{Distribution of study inmates according to gender}

A total of 870 inmates were examined. Out of which $805(92.5 \%)$ were males and $65(7.5 \%)$ were females.

\section{Distribution of study inmates according to age groups}

The minimum subject age was 18 years while the maximum was 85 years. Majority of the study population i.e. $318(36.6 \%)$ belonged to $25-34$ year and $203(23.3 \%)$ belonged to 35 - 44years age group, with the remaining of $187(21.5 \%), 100(11.5 \%), 46(5.3 \%)$ and $16(1.8 \%)$ belonging to the $18-24$ years, $45-54$ years, $55-64$ years and 65 and above age groups respectively.

\section{Distribution of study population accordingto literacy status}

The education level varied among the inmateswith majority of them were illiterate196 (22.5\%), inmates who studied till primaryschool were 177 (20.3\%), who studiedtill high school were $168(19.3 \%)$, thosewho studied till middle school were $160(18.4 \%)$ and $130(14.9 \%)$ were intermediates.On the other hand $3(0.3 \%)$ were professionals,36 $(4.1 \%)$ were graduates and Post-graduates.

\section{Distribution of study inmatesaccording to occupation}

While questioning, it was found that majorityof inmates examined belonged tofarmer, shop owner group 226(26.0\%), followed by unemployed 161(18.5\%), unskilledworker 160(18.4\%), Semi-skilledworkers 159 $(18.3 \%)$, skilled workers $134(15.4 \%)$. A total of $25(2.9 \%)$ and 5(0.6\%)inmates were semi-professionals and professionals. 


\section{Distribution of study populationaccording to Duration of Imprisonment}

Out of 870 inmates, $374(43 \%)$ were inprison for less than 3 years, $283(32.5 \%)$ for $3-6$ years, 184 $(21.1 \%)$ for $6-10$ yearsand $29(3.3 \%)$ for more than 10 years.

\section{Distribution of study population basedon frequency of dental visits}

It was found that $468(53.8 \%)$ of the inmateshad never visited dentist in their lifetime and 402 (46.2\%) of them had madepast dental visits for dental treatments andtheir problems.

\section{Distribution of study populationbased on past dental care received}

In total inmates, $399(45.9 \%)$ received dentalcare in their life, whereas $471(54.1 \%)$ never received any kind of treatment.

\section{Distribution of study populationbased on Dental Care Receivedduring Imprisonment}

Among the study population 113 (13\%)inmates received dental care during theirstay in the prison.

\section{Distribution of the study populationbased on Oral Hygiene Aids Used}

Majority of the study inmates used fingerwith toothpaste or powder i.e. 373 (42.9\%), $302(34.7 \%)$ used toothbrush withtoothpaste/powder and 157 (18\%) usedneem stick/ datoon to clean their teeth, whereas $38(4.4 \%)$ inmates did not use anyaid to clean their teeth.

\section{Prevalence of TMJ Disorders}

Out of 870 inmates, $554(63.7 \%)$ inmateswere suffering with problems regarding Temporo- mandibular joint disorder. (Table1)Out of 870 inmates, 341 (39.4\%) reportedclicking sound at TMJ, 103 (11.7\%) reportedtenderness at TMJ while opening themouth and 110(12.6\%) inmates were notable to open their mouth more than $30 \mathrm{~mm}$. Whereas $316(36.3 \%)$ were free from TMJ problem.(Table 1).

\begin{tabular}{|l|l|l|}
\hline \multicolumn{2}{|c|}{ Table 1: Distribution of study population according to TMJ sign and symptoms } \\
\hline TMJ Symptoms & Number Of Inmates (N) & Percentage (\%) \\
\hline Absent & 316 & $36.3 \%$ \\
\hline Present & 554 & $63.7 \%$ \\
\hline Total & 870 & $100 \%$ \\
\hline TMJ Signs & & \\
\hline No Signs & Signs Number Of Inmates & Percentage (\%) \\
\hline Clicking & 316 & $36.3 \%$ \\
\hline Tenderness & 341 & $39.4 \%$ \\
\hline Reduction In Opening $(<30 \mathrm{~mm})$ & 103 & $11.7 \%$ \\
\hline Total & 110 & $12.6 \%$ \\
\hline
\end{tabular}

\section{Prevalence of Oral Mucosal Lesions}

The overall prevalence of Oro-mucosal lesionswas 520(59.8\%), 350(40.2\%) of theinmates had no abnormal condition followed by $271(31.1 \%)$ with Leukoplakia, 156(17.9\%) with ulceration, 31(3.6\%) with lichen planus, $35(4 \%)$ with candidiasis, $25(2.9 \%)$ with acute necrotizing gingivitis, whereas $2(0.2 \%)$ were having abscess. (Table 2)

\begin{tabular}{|l|l|l|}
\hline \multicolumn{2}{|c|}{ Table 2: Prevalence of Oro- Mucosal Lesions Among the Study Population } \\
\hline Oral Mucosal & Lesion Number Of Inmates ( N) & Percentage ( \% ) \\
\hline No Abnormal Condition & 350 & $40.2 \%$ \\
\hline Malignant Tumour & $00 \%$ & $00 \%$ \\
\hline Leukoplakia & 271 & $31.1 \%$ \\
\hline Lichen Planus & 31 & $3.6 \%$ \\
\hline Ulceration & 156 & $17.9 \%$ \\
\hline Acute Necrotizing Gingivitis & 25 & $2.9 \%$ \\
\hline Candidiasis & 35 & $4.0 \%$ \\
\hline Abscess & 2 & $0.2 \%$ \\
\hline Other Conditions & 00 & $00 \%$ \\
\hline Total & $\mathbf{8 7 0}$ & $\mathbf{1 0 0} \%$ \\
\hline Normal Inmates & Total Inmates & Inmates With Lesions \\
\hline 350 & 870 & $870-350=520(59.8 \%)$ \\
\hline
\end{tabular}




\section{Prevalence of Dental Fluorosis among study population (Dean's Fluorosis Index)}

Among all the inmates $(n=870)$ examined, none was free from dental fluorosis. Mild fluorosis among $510(58.6 \%)$ and moderate fluorosis were present among 242(27.8\%) inmates followed by very mild fluorosis among $69(7.9 \%)$ and severe fluorosis among $37(4.3 \%)$ inmates.

\section{Periodontal Status (CPI) of the study population according to Duration of Imprisonment}

It was found that $222(59.3 \%)$ inmates who had been imprisoned for 1 to 3 years had calculus, 93(24.8\%) had shallow pockets, $42(11.2 \%)$ had deep pockets and 13(3.4\%) were having bleeding on probing. It was observed that, among the inmates imprisoned for $3-6$ years, only $3(1.06 \%)$ inmates had bleeding on probing with majority having calculus $131(46.2 \%)$, shallow pockets among $82(28.9 \%)$ and $65(22.9 \%)$ inmates were having deep pockets. In the inmates imprisoned for $6-10$ years, $76(41.3 \%)$ showed the presence of calculus deposits, followed by 53(28.8\%), 50(27.1\%) inmates exhibiting shallow pockets, deep pockets respectively.

Among inmates imprisoned for more than 10 years, only 4(13.7\%) showed presence of calculus deposit, followed by $10(34.4 \%)$ and $13(44.8 \%)$ inmates exhibiting shallow pockets and deep pockets respectively. A significant difference in CPI scores $(\mathrm{p}<0.05)$ were observed among the inmates with respect to period of imprisonment (Table 3).

\begin{tabular}{|c|c|c|c|c|c|}
\hline \multirow[t]{2}{*}{ CPI score } & \multicolumn{4}{|c|}{ Duration of imprisonment ( years ) } & \multirow[t]{2}{*}{ Total } \\
\hline & 1-3 & 3-6 & 6-10 & $>10$ & \\
\hline $0=$ healthy & $0 \%$ & $0 \%$ & $0 \%$ & $0 \%$ & $00 \%$ \\
\hline $1=$ bleeding & $13(3.4 \%)$ & $3(1.06 \%)$ & $0 \%$ & $0 \%$ & $16(1.8 \%)$ \\
\hline $2=$ calculus & $222(59.3 \%)$ & $131(46.2 \%)$ & $76(41.3 \%)$ & $4(13.7 \%)$ & $433(49.8 \%)$ \\
\hline $3=4-5 \mathrm{~mm}$ pocket & $93(24.8 \%)$ & $82(28.9 \%)$ & $53(28.8 \%)$ & $10(34.4 \%)$ & $238(27.4 \%)$ \\
\hline $4=$ pocket $6 \mathrm{~mm}$ or more & $42(11.2 \%)$ & $65(22.9 \%)$ & $50(27.1 \%)$ & $13(44.8 \%)$ & $170(19.5 \%)$ \\
\hline $5=$ excluded & $4(1.06 \%)$ & $2(0.7 \%)$ & $5(2.7 \%)$ & $2(6.8 \%)$ & $13(1.5 \%)$ \\
\hline Total & $374(100 \%)$ & $283(100 \%)$ & $184(100 \%)$ & $29(100 \%)$ & $870(100 \%)$ \\
\hline \multirow[t]{2}{*}{ LOA score } & \multicolumn{4}{|c|}{ Duration of imprisonment ( years ) } & Total \\
\hline & 1-3 & 3-6 & 6-10 & $>10$ & \\
\hline $0=0-3 \mathrm{~mm}$ & $183(48.9 \%)$ & $103(36.3 \%)$ & $46(25 \%)$ & $0 \%$ & $332(38.2 \%)$ \\
\hline $1=4-5 \mathrm{~mm}$ & $106(28.3 \%)$ & $103(36.3 \%)$ & $62(33.6 \%)$ & $15(51.7 \%)$ & $286(32.9 \%)$ \\
\hline $2=6-8 \mathrm{~mm}$ & $53(14.1 \%)$ & $50(17.6 \%)$ & $45(24.4 \%)$ & $10(34.4 \%)$ & $158(18.2 \%)$ \\
\hline $3=9-12 \mathrm{~mm}$ & $27(7.2 \%)$ & $26(9.1 \%)$ & $20(10.8 \%)$ & $2(6.8 \%)$ & $75(8.6 \%)$ \\
\hline $4=>12 \mathrm{~mm}$ & $1(0.26 \%)$ & $0 \%$ & $4(2.1 \%)$ & $0 \%$ & $5(0.6 \%)$ \\
\hline $5=$ excluded & $4(1.06 \%)$ & $1(0.3 \%)$ & $7(3.8 \%)$ & $2(6.8 \%)$ & $14(1.6 \%)$ \\
\hline Total & $374(100 \%)$ & $283(100 \%)$ & $184(100 \%)$ & $29(100 \%)$ & $870(100 \%)$ \\
\hline
\end{tabular}

\section{Distribution of loss of attachment scores according to Duration of Imprisonment}

Inmates $27((7.2 \%), 53(14.1 \%), 106(28.3 \%)$ imprisoned for period for 1-3years showed the loss of attachment of 9-12mm, 6-8mm and 4-5mm respectively. Inmates 26(9.1\%), 50(17.6\%), 103(36.3\%) imprisoned for $3-6$ years showed loss of attachment of $9-12 \mathrm{~mm}, 6-8 \mathrm{~mm}$ and $4-5 \mathrm{~mm}$ respectively. Around 184 inmates which were imprisoned for 6-10years, among them only 4(2.1\%) showed loss of attachment of more than $12 \mathrm{~mm}, 20(10.8 \%), 45(24.4 \%)$ inmates showed loss of attachment of $9-12 \mathrm{~mm}, 6-8 \mathrm{~mm}$ respectively.

Only $2(6.8 \%)$ inmates which were imprisoned for more than 10years showed loss of attachment of $9-12 \mathrm{~mm}$, $10(34.4 \%), 15(51.7 \%)$ inmates showed loss of attachment of $6-8 \mathrm{~mm}, 4-5 \mathrm{~mm}$ respectively. There was highly statistically significant differences in loss of attachment scores between the inmates imprisoned for different period of imprisonment $(\mathrm{p}=0.000)$ (Table 3$)$.

\section{Prevalence of dental caries amongthe study population}

Out of 870 inmates, $185(21.3 \%)$ inmateswere free from dental caries. Six hundredand ninety five (78.7\%) inmates had dental caries. Inmates 156(17.9\%), 150(17.2\%), 135(15.5\%), 89(10.2\%), 48(5.5\%) were having caries in their 3, 4, 2, 5, and 6 teeth respectively. (Table 4).

\begin{tabular}{|l|l|l|}
\hline \multicolumn{3}{|c|}{ Table 4: Prevalence of Dental Caries Among the Study Population } \\
\hline $\begin{array}{l}\text { Number of teeth affected by caries (N } \\
)\end{array}$ & Number of inmates (N) & Percentage (\%) \\
\hline 0 & 185 & $21.3 \%$ \\
\hline 1 & 85 & 9.8 \\
\hline 2 & 135 & $155 \%$ \\
\hline 3 & 156 & $17.9 \%$ \\
\hline 4 & 150 & $17.2 \%$ \\
\hline 5 & 89 & $10.2 \%$ \\
\hline
\end{tabular}


Oral Health Status And Treatment Needs Of Inmates In District Jail Of Jaipur City - A ....

\begin{tabular}{|l|l|l|}
\hline 6 & 48 & $5.5 \%$ \\
\hline 7 & 15 & $1.7 \%$ \\
\hline 8 & 0 & $00 \%$ \\
\hline 9 & 6 & $\mathbf{0 . 7 \%}$ \\
\hline $\mathbf{1 0}$ & 1 & $0.1 \%$ \\
\hline Total & $\mathbf{8 7 0}$ & $\mathbf{1 0 0 \%}$ \\
\hline
\end{tabular}

Prevalence of dental caries according to Period of Imprisonment

Two hundred and eighty one (75.2\%) inmates imprisoned for $1-3$ years were suffering from caries, followed by 232(82\%), 151(82.1\%), 21(72.5\%), inmates imprisoned for 3-6years, 6-10years, more than 10 years were affected by caries respectively (Figure 1).

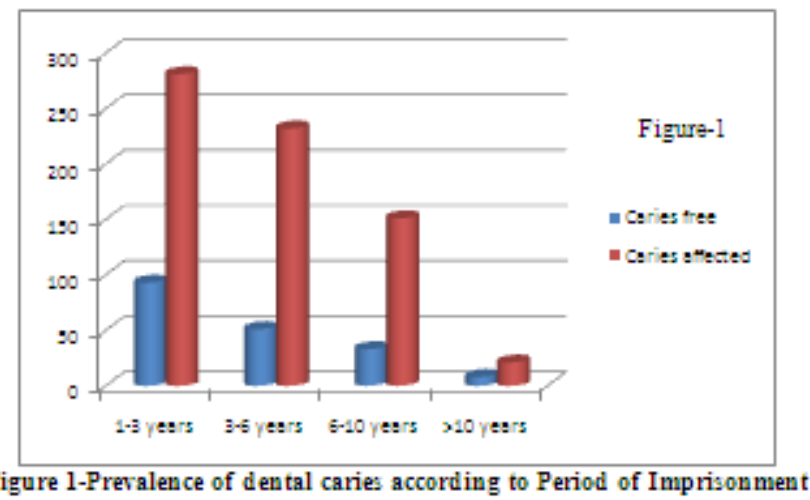

Prevalence of teeth with trauma among the study population

Out of 870 inmates, 215(24.7\%) inmates were having broken teeth because of trauma. One hundred six (12.2\%) inmates were having 1 traumatic tooth, 95(10.9\%) inmates were having 2 teeth broken. Eleven (1.3\%), one $(0.1 \%)$ and two $(0.2 \%)$ inmates were having $3,4,5$ traumatic teeth.

\section{Distribution of study population according to Prosthetic Need}

In maxillary arch $147(16.9 \%)$ inmates needed one unit prosthesis, $127(14.6 \%)$ inmates were in need of multiunit prosthesis, 96(11\%) needed combination of one and /or multiunit prosthesis, and 15(1.7\%) needed full prosthesis. In mandibular arch, the prosthetic need of the inmates were $128(14.7 \%)$ for one unit prosthesis, $113(13 \%)$ for multiunit prosthesis, $149(17.1 \%)$ for combination of one and /or multiunit prosthesis, and $14(1.6 \%)$ had need for full prosthesis (Figure 2).

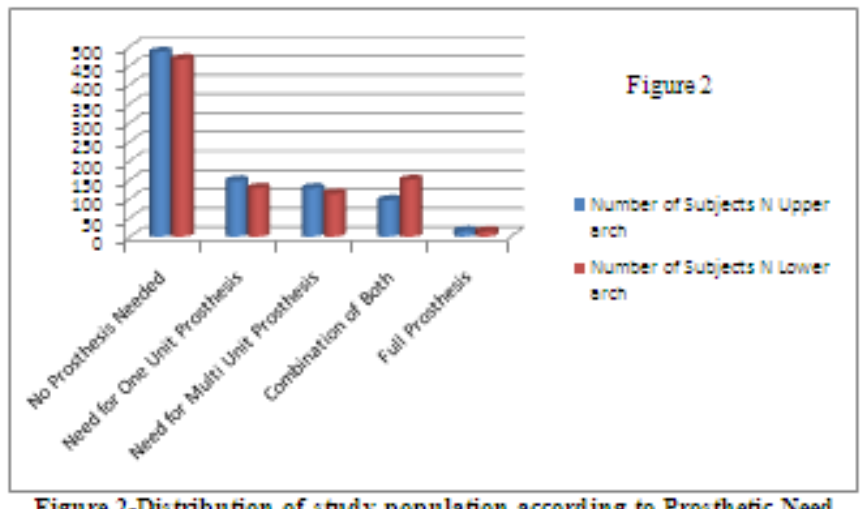

\section{Distribution of study population according to need for Immediate Care}

A total of $286(32.9 \%)$ inmates were having life threatening conditions, and needed immediate attention and referral (Figure 3). 


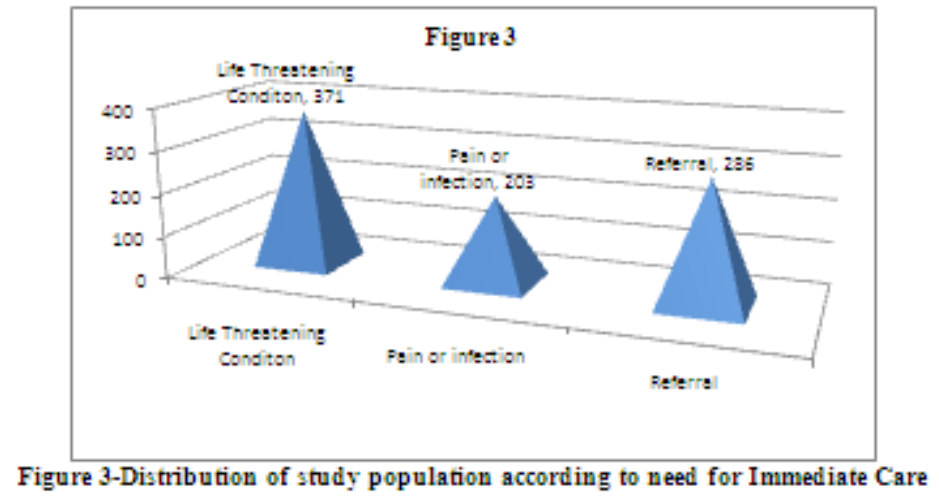

\section{Distribution of study population according to treatment needs}

Out of 870 inmates, $413(47.5 \%)$ and 476(54.7\%) inmates need one surface and two surface restoration of decayed tooth. Whereas $256(29.4 \%), 355(40.8 \%), 460(52.9 \%)$ inmates need pulp care, extraction, and prosthetic replacement respectively (Figure 4).

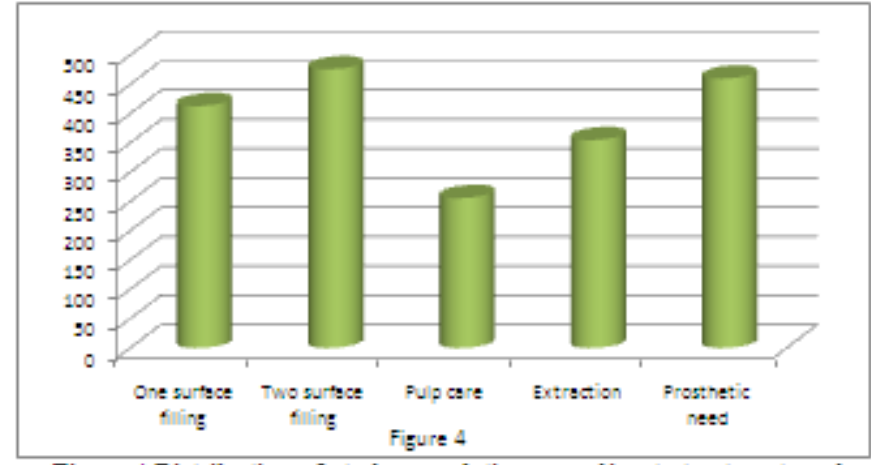

Figure 4-Distribution of study population according to treatment need

\section{Discussion}

The prison population is a unique and challenging one with many problems, including poor health. Dental diseases can reach epidemic proportions in the prison settings. The purpose of the present study was to assess the oral health status of the prisoners in the District Jail of Jaipur. In particular, their oral health was assessed and specific attention was paid towards their level of unmet dental treatment needs.

The heterogeneity of population was studied and methods of assessment precluded simple generalization, but the pattern appeared to be that the oral health status of inmates was poor.

\section{Demographic Details}

Majority of the inmates were illiterate $196(22.5 \%)$ and were unemployed or farmers. These finding were in contrast with prison Inmates of Central Prison Bangalore by Dr. Uma SR et al. 2011, (8) where majority of prison inmates $764(58.4 \%)$ had achieved more than secondaryeducation. Findings reported regarding education status of Remand Prisoners in Brixton, London (2) and on Institutionalized Older People in NorthEast Brazil (9) were similar to the present study.

\section{Oral Hygiene Practices}

The jail authorities do not provide oral cleaning materials to the inmates, therefore large proportion of $373(42.9 \%)$ of the inmates used finger and tooth paste/powder and 302(34.7\%) used tooth brush and toothpaste/toothpowder for cleaning their teeth in this study. This shows that they are least concerned about their oral health. The present findings are not similar to the study conducted by Nobile C G A et al (10) which stated that $96 \%$ of the population in their study used tooth brush and tooth paste. M. Osborn et al in 2003 (11) observed that $86 \%$ of the subjects brushed their teeth using tooth brush and tooth paste. Present study results are quite similar to results reported by Luciene Ribeiro Gaiao et al, 2009 (9) where only 53\% studypopulation uses toothbrush as a cleaning aid. This pattern of brushing habit reported is due to study being conducted among older population where most of the study samples were edentulous. 


\section{Past dental visits and care}

402(46.2\%) inmates in our study had visited the dentist out of which 399(45.9\%) had received care. Study findings were in accordance with the studies conducted by Nobile CGA et al [2007] (10) (39.15\%), Bansal V et al [2010] (12) (36.8\%), Osborn M et al [2003] (11) (62\%). A study conducted by Jones et al [2002] (13) among Scottish prisons, also revealed the same result in $58.5 \%$ prisoners visited the dental surgeon. The reason for the visit in our studymay be because of frequent treatmentcamps being organized in the hospitalwithin the jail premises.

\section{Oral Mucosal Lesions}

The prevalence of oral-mucosal lesions has variation among the inmates. The overall prevalence of oral-mucosal lesions among the inmates of our study was $59.8 \%$. The results of the present study are high compared to the study conducted by Uma SRand Hiremath SS [2011] (8) in Karnataka inIndia. The prevalence of oral-mucosal lesionwas $12 \%$ in that study. In our study, the most common mucosal lesions wereleukoplakia(31.1\%). This result is highercomparable to study conducted by VeeraReddy [2012] (14) in which the prevalenceof leukoplakia was $1.1 \%$. This might bebecause of excessive use of tobacco in the Jaipur jail, to overcome the stress.

In our study, the prevalence of white lesionswere leukoplakia (31.1\%) and lichenplanus (3.6\%), it was in accordance with the study conducted by Uma SR andHiremath SS [2011]. (8) Oro-mucosal conditionsand diseases may be caused by localdiseases, systemic diseases, drug related reactionsor life style factors such as consumptionof tobacco, betel chew or alcohol[Harris CK, 2004], (15) also other factorstrauma, effects of medication and oral anddenture hygiene [Jainkittivong A, 2002] (16)also play a role in the causation.

\section{Periodontal Status (CPI):}

It was observed that none of the inmatesin the study population had healthy periodontalcondition. This was in accordancewith the findings by McGrath C [2002] (17)and James H Clare [2002]. (18) Whereas, Nobile CGA et al [2007] (10) found that $10.5 \%$ of the study sample had healthysextants in a study conducted at Italy. It was observed that $49.8 \%$ of the studysample had a CPI score of 2, which wasnot in agreement with the results obtainedby Barnes GP et al [1987] (19) who foundthat 32\% of the study subjects had a CPIscore of 2. In other study done by McGrath[200] (17) among the prisoners in HongKong detection centre; periodontal healthof prisoner's was assessed. The majority, $25.5 \%$ had a highest CPI score of two.

Formation of calculus may be attributedto various factors like negligence of oralhealth, improper brushing techniques andunavailability of oral hygiene aids [Uma SR,Hiremath SS, 2011]. (8)Approximately $27.4 \%$ and $19.5 \%$ of inmateshad a CPI score of 3 and 4 respectivelywith gingival pockets $4-5 \mathrm{~mm}$ and $>6 \mathrm{~mm}$. These findings were not in accordancewith the study done by McGrath [2002](17) who found that CPI scores of threeand four were recorded for $12.27 \%$ and6.13\% subjects respectively. In a study conductedby Cobert et al [2001], (20) in SouthernChina, subjects underwent periodontalexamination; few $(<1 \%)$ had healthyperiodontal conditions in the absence ofcalculus. Most subjects in all age groupsscored either calculus (61\%) or shallowpockets $(34 \%)$, and only a small proportionwere recorded as having deep pockets(5\%). In a study conducted on institutionalizedelderly in Hong Kong by Lo et al[2004]. (21) The percentage of subjects withCPI scores were 1\% (CPI-0), 2\% (CPI-1),41\% (CPI-2), 37\% (CPI-3) and 20\% (CPI-4) respectively. This may be attributed to a lack of oral health maintenance and also the various types of stressors experienced by the inmates. It proves the fact that these inmates need thorough oral hygiene care by the dental professionals along with good dental health education to improve the existing situation.

\section{Loss of Attachment}

In the present study $38.2 \%$ of the study population had a loss of attachment score of $0(0-3 \mathrm{~mm})$. and $32.9 \%$ of the inmates had a score of $4-5 \mathrm{~mm}$, loss of attachment i.e. code 1 . Our study results are not similar to a study conducted by Thakare V et al [2010] (22) among institutionalized individuals where she demonstrated that $11.53 \%$ of the study subjects had a score of 0 and $64.42 \%$ scored 1 in loss of attachment.

The probable reason for poor periodontal health might be associated with oral hygiene practices among the prison inmates and the education attainment among the prison inmates was poor. Majority of prisoners were not educated.

\section{Caries Prevalence}

Dental caries experience was measured as the number of decayed, missing or filled permanent teeth (DMFT) using the WHO Dentition Status and Treatment Need. The prevalence of dental caries in our study was $78.7 \%$ with the mean DMFT of 4.79. Nobile CGA et al [2007] (25) observed a mean DMFT score of 9.8 and the caries prevalence of $91.2 \%$ which is not in an accordance to present study. Present study results are also not similar to other studies conducted by ME Salive and Carolla JM [1989] (23) where the prevalence of caries was 
found to be $95 \%$. Study conducted by Naidoo S et al [2005] (24) reported a mean DMFT of 15.45 which was very high compared to the present study. In the study by MA Cunningham et al [1985] (25) they reporteda mean DMFT of 10.53 and Victor Badner [1994] (26) in his study obtained a mean DMFT of 9.9. McGrath C [2002] (17) reported a mean DMFT of 22.5. In study conducted by E. Heidari et al [2007] (2)among Brixton prisoners, they had a mean DMFT of 14.2. Hiremath V P [2009] (27) reported mean DMFT of 5.22 which was in accordance with the results of the present study. This prevalence of dental caries inthe present population is due to the fact that dental caries is a multi-factorial disease influenced by many factors including lifestyle factors, type of diet, lack of oral hygiene measures and cultural factors beforecoming to the jail. Inmates depend on prison authorities to arrange dental care.

The high prevalence due to the fact that untreated dental decay is greater in prison population [Lars Moller et al, 2007]. (28)The high prevalence may be attributed to the low utilization of preventive and therapeutic dental services and inadequate dental personnel for the prison inmates.

\section{Treatment Need}

In the present study $44.3 \%$ inmates need prosthesis in the maxillary arch and $46.4 \%$ inmates need prosthesis in mandibular arch which was not in contrast to study done by Uma SR and Hiremath SS [2011]. (8) Among the inmates it was observed that $14.6 \%$ in maxillary and $13 \%$ in mandibular arch need more than one tooth replacement, while $1.7 \%$ and $1.6 \%$ required complete denture in maxillary and mandibular arch respectively. This can be due to high incidence of caries and periodontal disease. With increasing age, attitudes towards oral health and their care seeking behaviors and the limited options of treatment modalities [Smith.J. M, 1980]. (29) In our study $78.7 \%$ inmates required restorations, $29.4 \%$ required pulp care whereas $40.8 \%$ inmates needed extraction of grosslydecayed teeth. In results reported by Scottishprison's Dental Health Survey by Joneset al [2002], (30) where 31\% inmate's needsrestorative care and 28.8\% required endodontictreatments and in another studyconducted by Heidari et al [2007] (2) in HMPBrixton, London reported very high needfor restorative care among prisoners wasreported. These findings were found to bein accordance to the present study.In the present study, it was found that286(32.9\%) inmates were suffering fromlife threatening conditions like leukoplakiaetc and required referral to the hospital havingdental settings as they required urgenttreatment. Prisoners have significantly greater oralhealth needs than the general population.Many prisoners are unemployed beforebeing sentenced and come from communitieswith a high level of social exploitation.The demand for prison dental serviceshas continued to increase in last fewdecades, especially because the numbers ofinmates have increased and hence, there isthe need to be more responsive to theirclinical needs.

The normative needs should be convertedinto a demand for dental care which involvesrising the perceived need. To lead agood quality of general health it is necessaryto have good oral health which is contributoryto the general health of the individual.It is necessary to improve the healthof the inmates since they are available duringthe incarcerated period as stated by TMarshall [2001]. (31)

\section{Limitations Of The Study}

- The major limitation of the study wasits cross sectional nature, which limitedour ability to relate the time patternwith the risk factors and their complications.

- More refined and informational resultscould be obtained if the present studyinference would be compared with non-prisoner population, questioned andexamined by the same codes and criteria.

\section{Conclusion}

Providing access to appropriate dental carefor the underserved segments of the populationis a complex problem that will notbe solved easily. Preventive measures toimprove dental care and provision of dentalhealth education are very much necessaryto ensure optimum oral health amongthe inmates. It is imperative that the specificbarriers to care for each group are identifiedand understood.

The results of the current study indicate that the inmates of Jaipur Jail had high prevalence of dental caries, oral mucosal lesions, poor periodontal status and varying degrees of dental fluorosis. It createsalarming need to focus on these risk groups with special emphasis on the factors which are contributing to the poor oral health status.

\section{References}

[1]. Colsher PL, Wallace RB, LoeffelholzPLet al. Health status of older maleprisoners: a comprehensive survey.American Journal of Public Health 1992;82(6):881-82.

[2]. Heidari E, Dickinson C, Wilson R, Fiske J.Oral health of remand prisoners in HMPBrixton, London. British Dental Journal2007;16.

[3]. Prison Heath. Available at http://www.prisons.tn.nic.in/history.htm;accessed on December 18, 2013.

[4]. Christine K. Heng, Douglas E. Morse.Dental caries experience of femaleinmates. Journal of Public HealthDentistry 2002;62(1):253-57. 
[5]. Berkman A. Prison health: the breakingpoint. Am J Public Health 1995;85(12):1616-18.

[6]. Peter S. Essentials of Preventive andCommunity Dentistry. Fourth Edition.Arya(Medi) publishing house; 2010.

[7]. WHO. Oral Health Surveys, Basicmethods, WHO 4th edition, Geneva;1997.

[8]. Uma SR, Hiremath SS. Oral Health Carefor inmates of central prison, BangaloreanInstitutionalized approach. Journal ofIndian Association of Public HealthDentistry 2011;17(suppl 1):297-304.

[9]. Luciene Ribeiro Gaiao, Maria EneideLeitao de Almeida, Jose Gomes BezerraFilho, et al. Poor Dental Status and OralHygiene Practices in InstitutionalizedOlder People in Northeast Brazil.International Journal of Dentistry 2009:1-6

[10]. Nobile CGA, Fortunato L, Pavia M et al.Oral health status of male prisoners inItaly. International Dental Journal2007;57:27-35.

[11]. Osborn M, Butler T, Barnard PD. Oralhealth status of prison inmates- NewSouth Wales, Australia. Australian DentalJournal 2003;48(1):34-38

[12]. Bansal V, Sogi GM, Veeresha KL.Assessment of Oral Health Status andTreatment needs of elders associatedwith elders' home of Ambala division,Haryana, India. Indian Journal of Dental

[13]. Research 2010;21(2):244-47.

[14]. Mixson JM, Eplee HC, Fell PH, Jones JJ,Rico M. Oral health status of a Federalprison population. Journal of PublicHealth Dentistry 1990;50(4):257-61.

[15]. Veera Reddy, ChadlavdaVenkantaKondareddy, SunithaSiddannaandMuryaManjunath. A survey on oral healthstatus and treatment needs of lifeimprisonedinmates in central jails of

[16]. Karnataka, India. International DentalJournal 2012;62:27-32.

[17]. Harris CK, Warnakulasuriya KA, CooperDJ, Peters TJ, et al. Prevalence of oralmucosal lesions in alcohol misusersinsouth London. Journal of Oral PathologyMedicine 2004;33:253-59.

[18]. Jainkittivong A, Aneksuk V, LanglaisRP.Oral mucosal conditions in elderly dentalpatients. Oral Diseases 2002;8:218-23.

[19]. Colman McGrath. Oral health behind bars.A study of oral disease and its impact onthe life quality of an older prisonpopulation.Gerodontology 2002;19(2):109-14.

[20]. James H Clare. Dental Health status,unmet needs, and utilization of servicesin a cohort of adult felons at admissionand after three years' incarceration.Journal of Correctional Health Care

[21]. 2002;9(1):65-76.

[22]. Barnes GP, Parker WA, Fultz RP, et al.Periodontal treatment requirements ofrecently incarcerated prison inmates.Journal of Periodontal Research 1987;22:422-25.

[23]. Corbet EF, Wong MCM, Lin HC. Periodontalconditions in adult Chinese. Journal ofDental Research 2001;80(5):1480-85.

[24]. Lo EC, Luo Y, Dyson JE. Oral health statusof institutionalized elderly in Hong Kong.Community Dent Health 2004;21(3):224-26.

[25]. Thakare V, Krishnan ACG. PeriodontalStatus, Prosthetic Status and ProstheticNeedsAmongIntitutionalizedGeriatricIndividuals in Vadodara City, Gujrat - ADescriptive Study. Journal of IndianAssociation of Public Health Dentistry2010;15:153-58.

[26]. Salive M E, Carolla JM, Brewer TF. Dentalhealth of male inmates in a state prisonsystem. Journal of Public HealthDentistry 1989;49(2):83-86.

[27]. Naidoo S, Yengopal V, Cohen B. Abaseline survey: oral health status ofprisoners - Western Cape. Journal ofthe South African Dental Association2005;60(1):24-27.

[28]. Cunningham MA, Glenn RE, Field HM,Jakobsen JR. Dental disease prevalencein a prison population. Journal of PublicHealth Dentistry 1985;45(1):49-52.

[29]. Victor Badner, Robert Margolin. Oralhealth status among women inmates atRikers Island Correctional facility. Journalof Correctional Health Care1994;1(1):55-72.

[30]. Hiremath VP. Oral Health Status andTreatment Needs of the inmates inHindalga Central Prison, Belgavi-Karnataka. Journal of Indian Associationof Public Health Dent 2009;14:1-6.

[31]. Lars Moller, Heino Stover, Ralf Jürgens,Alex Gatherer, HaikNikogosian. Health inprison: A WHO guide to the essentials inprison health. WHO, Europe 2007.

[32]. Smith JM, Sheiham A. Dental treatmentneeds and demands of an elderlypopulation in England. CommunityDentistry and Oral Epidemiology 1980;8:360-64.

[33]. Colwyn M Jones, Mary McCann, ZoannNugent. Scottish prisons Dental HealthSurvey 2002.

[34]. Marshall T, Simpson S, Stevens A. Useof health services by prison inmates:Comparisons with the community.Journal of Epidemiology of CommunityHealth 2001;55:364-65. 